\title{
The Antidiabetic Effectivity of Indonesian Plants Extracts via DPP-IV Inhibitory Mechanism
}

\author{
Erwi Putri Setyaningsih', Fadlina Chany Saputri ${ }^{2}$, Abdul Mun'im ${ }^{3}$ \\ ${ }^{1}$ Faculty of Pharmacy, Universitas Indonesia, Depok, West Java, INDONESIA. \\ ${ }^{2}$ Faculty of Pharmacy, Programme of Herbal Medicine, Universitas Indonesia, Depok, West Java, INDONESIA. \\ 3Department of Pharmacognosy-Phytochemistry, Faculty of Pharmacy, Universitas Indonesia, Depok, West Java, INDONESIA.
}

\begin{abstract}
Background: Nature provides a rich source of antidiabetic medicines. More than 1.200 plants have been reported to have anti-diabetic activities and more than half of the drugs on the market come from natural products. Therefore, research for developing new antidiabetic drugs from natural sources is necessary to properly evaluate various mechanism of action, efficacy and safety at toxicological, physiological, pharmacological and molecular levels before these drugs applied in treatment of diabetes. This study aims to examine and determine the highest activity of 10 ethanol extracts from Indonesian plants selected for in vitro inhibitory activity of dipeptidyl peptidase - IV (DPP-IV). Materials and Methods: This research studied DPP-IV inhibitory mechanism from 10 plant extract, namely Caesalpinia sappan, Cinchona officinalis, Elephantopus scaber, Foeniculum vulgare, Morus nigra, Muntingia calabura, Phyllanthus niruri, Psidium guajava, Rheum palmatum and Vernonia amygdalina using the spectrophotometric method and Sitagliptin as a positive control. The effectiveness of inhibition was assessed by percent inhibition. Tannin removal test was performed to exclude false-positive results. Results: The ethanolic extract of Caesalpinia sappan exhibited DPP-IV inhibitory activity greater than $80 \%$, which was not markedly different from that of Sitagliptin at $85 \%$. Brazilin, an active
\end{abstract}

compound from Caesalpinia sappan gave the inhibition at greater than $78 \%$. Tannin removal test for Caesalpinia sappan gave the inhibition at $74.16 \%$. The High Performance Liquid Chromatography (HPLC) analysis result displayed that brazilin content on Caesalpinia sappan extract was 91.94\%. Conclusion: Based on these results, Caesalpinia sappan ethanol extract has a potential effect as a better antidiabetic agent than other extracts used in this study.

Key words: Antidiabetic, DPP-IV, Caesalpinia sappan, Inhibitory activity.

\section{Correspondence}

Dr. Abdul Mun'im, Professor at Department of Pharmacognosy-Phytochemistry, Faculty of Pharmacy, Universitas Indonesia, Depok, 16424, West Java, INDONESIA.

JSS Academy of Higher Education and Research, Mysuru, Karnataka- 570015, INDIA.

Phone: +62 85216104550

Email: munim@farmasi.ui.ac.id

DOI: 10.5530/jyp.2019.11.34

\section{INTRODUCTION}

Diabetes mellitus (DM) is the fastest growing metabolic disease all over the world, identified by approximately 285 million people who have been diagnosed with DM to date, with this number predicted to increase by the year 2030 ${ }^{1,2}$ There are some mechanisms of antidiabetic drugs and currently the category of antidiabetic drugs working on the incretin pathway is more desirable. ${ }^{3}$ Incretin consists of a Glucose-dependent Insulinotropic Polypeptide (GIP) and Glucagon-Like Peptide-1 (GLP-1). However, GLP-1 has a short half-life $(<2 \mathrm{~min})$ caused by its fast cleavage by DPP-IV. ${ }^{4}$ Therefore, DPP-IV inhibitors are the newest class of antidiabetic drugs approved by the FDA. ${ }^{5}$

Several synthetic DPP-IV inhibitors are available in the market such as sitagliptin, vildagliptin, saxagliptin and alogliptin. These synthetic drugs are expensive in their long term use for the purposes of therapy. Moreover, the study has shown that prolonged usage of these drugs causes unacceptable adverse effects such as pancreatitis, angioedema and infective disorders. ${ }^{6}$ The development of antidiabetic agents including natural products, is necessary to obtain drugs that are safe and have more efficient activity.

Jamu as a traditional medicine has been used in Indonesia for some generations. There are a number of experimental studies on type 2 diabetes that have reported that some herbs in jamu ingredients have been used in type 2 diabetes therapy and these drugs have been approved in human and animal research. ${ }^{7,8}$ It is assumed that herbal medicine provides a vulnerable alternative to treatment of type 2 diabetes. The
Diabetic Committee of the World Health Organization has made the recommendation for further research on herbal medicine as a treatment for diabetes. ${ }^{9}$

Stilbenes are polyphenolic compounds known to reduce postprandial blood glucose concentration levels. ${ }^{10}$ Resveratrol, a stilbene derivative effectively contributes to the protection of $\beta$ cells in diabetes and reduces insulin levels in animals. ${ }^{11,12}$ These data showed that herbs containing stilbene may be useful in preventing and treating diabetes.

The extracts which contain stilbene are Caesalpinia sappan, Cinchona officinalis, Elephantopus scaber, Foeniculum vulgare, Morus nigra, Muntingia calabura, Phyllanthus niruri, Psidium guajava, Rheum palmatum and Vernonia amygdalina and they have been adopted for antidiabetic therapy, with their pharmacological properties being widely explored to develop new DPP-IV inhibitors. ${ }^{13}$ Based on this background this study aimed to evaluate 10 ethanolic extracts of selected Indonesian plants for in vitro inhibitory activity of DPP-IV.

\section{MATERIALS AND METHODS}

\section{Extracts and chemicals}

The extracts of Caesalpinia sappan, Cinchona officinalis, Elephantopus scaber, Foeniculum vulgare, Morus nigra, Muntingia calabura, Phyllanthus niruri, Psidium guajava, Rheum palmatum and Vernonia amygdalina were collected from Kebun Raya Bogor. The standard of Brazilin 
(MP Biomedicals, France), DPP-IV Assay kit (Cayman Chemical, USA), ethanol (Merck, Germany) and aquadest. Reagents for HPLC analysis were analytical grade and purchased from a local distributor.

\section{Extraction}

The powder of the dried plants, $10 \mathrm{~g}$ were macerated with $100 \mathrm{~mL}$ of $80 \%$ ethanol. The extracts were evaporated with a rotary vacuum evaporator (Buchi, Switzerland).

\section{DPP-IV activity assay}

The DPP-IV-Glo ${ }^{m}$ Assay was used to measures dipeptidyl peptidase IV (DPP-IV) inhibitor activity and was determined using Glomax (Promega, USA), with an excitation wavelength of $350-360 \mathrm{~nm}$ and emission wavelength of $450-465 \mathrm{~nm} .{ }^{14}$ The samples were reconstituted in $80 \%$ ethanol to a final concentration of $1000 \mathrm{ppm}$. The assay used 96-wells microplate and the reaction per well included. $10 \mu \mathrm{L}$ of the test sample mixed with $30 \mu \mathrm{L}$ of assay buffer solution and $10 \mu \mathrm{L}$ of DPP-IV solution. Enzyme control was prepared using $80 \%$ ethanol instead of the sample. Inhibitor control (Sitagliptin) was prepared using an inhibitor solution in place of the sample. Subsequently, $50 \mu \mathrm{L}$ of substrate $\mathrm{H}$-Gly-Pro-AMC substrate was added, then the microplate was incubated at $37^{\circ} \mathrm{C}$ for $30 \mathrm{~min}$. Each test sample was analyzed in triplicate. The details of pipetting can be seen in Table 1 .

\section{Calculation of percent inhibition}

Percent inhibition was calculated using the following formula in Eq. 1:

$$
\% \text { Inhibition }=\left(\frac{\text { Initial activity }- \text { inhibitor }}{\text { Initial activity }}\right) \times 100
$$

\section{Tannin elimination}

Gelatin solution of $1 \%$ was added to the test filtrate. The flask was shaken at $100 \mathrm{rpm}$ for $10 \mathrm{~min}$ at $25^{\circ} \mathrm{C}$. The supernatant was dried in a waterbath and vacuum oven, then dissolved with $80 \%$ ethanol to ensure the tannin effect of the extract on DPP-IV inhibitory activity. ${ }^{15}$

\section{Determination of brazilin in the extract by high Performance liquid chromatography (HPLC) analysis}

The ethanolic extract of Brazilin was determined by HPLC to calculate Brazilin content. The system on the isocratic mode, nucleosil $100 \mathrm{C}_{18}$ $(150 \mathrm{~mm} \times 4.6 \mathrm{~mm}, 5 \mu \mathrm{m})$ was used as a stationary phase with a flow rate of $1.0 \mathrm{~mL} / \mathrm{min}$. The solvent used for separation was $0.3 \%$ acetic acid: acetonitrile (85.5:14.5). Brazilin was used as a standard compound for quantitative analysis. The standard $1.000 \mathrm{ppm}$ Brazilin stock solution was performed by dissolving in $80 \%$ ethanol. Standard stock solutions were diluted to six standard solutions with concentrations of 200, 175, 150, 125, 100 and $75 \mathrm{ppm}$. Detection was carried out at $280 \mathrm{~nm}$ with the injection volume was $20 \mu$ and 5 min retention time. ${ }^{16}$

Table 1: Pipetting summary.

\begin{tabular}{|c|c|c|c|c|c|}
\hline & $\begin{array}{l}\text { Assay } \\
\text { Buffer }\end{array}$ & $\begin{array}{l}\text { DPP } \\
\text { (IV) }\end{array}$ & Solvent & Inhibitor & $\begin{array}{c}\text { Substrate } \\
\text { Solution }\end{array}$ \\
\hline $\begin{array}{c}100 \% \text { Initial } \\
\text { Activity }\end{array}$ & $30 \mu \mathrm{L}$ & $10 \mu \mathrm{L}$ & $10 \mu \mathrm{L}$ & & $50 \mu \mathrm{L}$ \\
\hline Background & $40 \mu \mathrm{L}$ & & $10 \mu \mathrm{L}$ & & $50 \mu \mathrm{L}$ \\
\hline $\begin{array}{l}\text { Sitagliptin } \\
\text { (Positive control } \\
\text { inhibitor) }\end{array}$ & $30 \mu \mathrm{L}$ & $10 \mu \mathrm{L}$ & & $10 \mu \mathrm{L}$ & $50 \mu \mathrm{L}$ \\
\hline Samples & $30 \mu \mathrm{L}$ & $10 \mu \mathrm{L}$ & & $10 \mu \mathrm{L}$ & $50 \mu \mathrm{L}$ \\
\hline
\end{tabular}

Table 2: DPP-IV inhibition activity of the extract and tannin elimination test.

\begin{tabular}{|c|c|c|c|}
\hline No & Samples (100 ppm) & Part of plants & Inhibition (\%) \\
\hline 1. & Sitagliptin (positive control) & & $85.18 \%$ \\
\hline 2. & Brazilin standard & & $78.30 \%$ \\
\hline 3. & Caesalpinia sappan & Heartwood & $84.25 \%$ \\
\hline 4. & Cinchona officinalis & Stem bark & $62.95 \%$ \\
\hline 5. & Elephantopus scaber & Roots & $48.17 \%$ \\
\hline 6. & Foeniculum vulgare & Seeds & $46.15 \%$ \\
\hline 7. & Muntingia calabura & Leaves & $74.12 \%$ \\
\hline 8. & Morus nigra & Stem bark & $51.0 \%$ \\
\hline 9. & Phyllanthns niuri & Aerial parts & $70.48 \%$ \\
\hline 10. & Psidium guajava & Leaves & $66.11 \%$ \\
\hline 11. & Rheum palmatum & Root & $72.67 \%$ \\
\hline 12. & Vernonia amygdalina & Leaves & $50.20 \%$ \\
\hline 13. & $\begin{array}{c}\text { Caesalpinia sappan } \\
\text { (tannin removal) }\end{array}$ & Heartwood & $74.16 \%$ \\
\hline 14. & $\begin{array}{l}\text { Cinchona officinalis } \\
\text { (tannin removal) }\end{array}$ & Stem bark & $22.50 \%$ \\
\hline 15. & $\begin{array}{l}\text { Phyllanthus niruri } \\
\text { (tannin removal) }\end{array}$ & Aerial parts & $27.20 \%$ \\
\hline 16. & $\begin{array}{l}\text { Psidium guajava } \\
\text { (tannin removal) }\end{array}$ & Leaves & $29.50 \%$ \\
\hline
\end{tabular}

\section{RESULTS}

\section{DPP-IV inhibitory activity assay}

The test results of DPP-IV inhibitory activity presented with percent inhibition values. The calculation result of the percent inhibition of the extract against DPP-IV enzyme can be seen in Table 2. The highest inhibitory activity of samples was obtained from Caesalpinia sappan extracts with percent inhibition value $84.25 \%$, while Sitagliptin as positive control resulted in inhibition of $85.18 \%$. Standard Brazilin was tested and gave the percent inhibition value of more than $78.30 \%$.

\section{Tannin elimination}

Tannin content on the extract was removed and investigated to exclude false-positive results. Percent inhibition of the Caesalpinia sappan (without tannin) was $74.16 \%$, Cinchona officinalis (without tannin) was $22.50 \%$, Phyllanthus niruri (without tannin) was $27.20 \%$, Psidium guajava (without tannin) was $29.50 \%$.

\section{Determination of brazilin in the extract by HPLC analysis}

The amount of Brazilin on Caesalpinia sappan extract was determined by the HPLC method. Ethanolic extract and the standard solution of Brazilin were analyzed at wavelength $280 \mathrm{~nm}$. The HPLC chromatogram of Caesalpinia sappan extract and Brazilin standard was shown in Figure 1. The linear equation for Brazilin was $y=1542.3 \mathrm{x}-2986.1$ $\left(R^{2}=0.9981\right)$. The test result showed that Brazilin content was $91.94 \%$.

\section{DISCUSSION}

Cayman's DPP-IV inhibitor screening assay used fluorescence-based method for screening DPP-IV inhibitors. This assay used the fluorogenic substrate Gly-Pro-Aminomethylcoumarin (AMC) to determine DPP-IV activity. DPP-IV releases the free AMC group by cleavage of peptide bond, resulting in fluorescence that can be analyzed using an excitation wavelength and emission wavelength. ${ }^{14}$ 


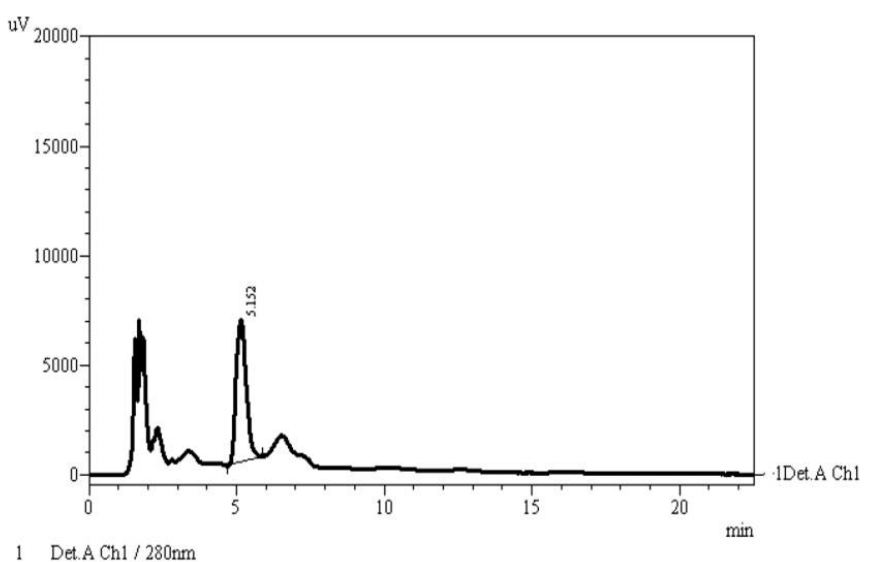

1 Det.ACh1/280nm

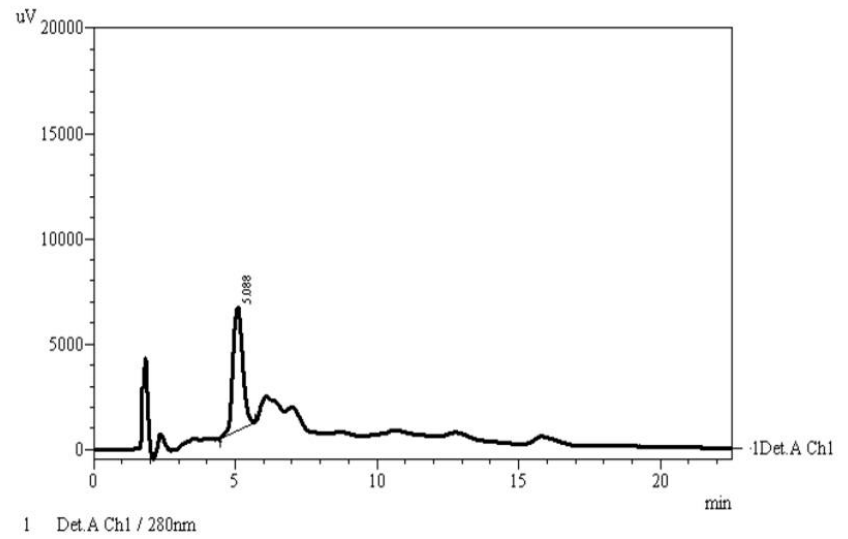

Figure 1: HPLC chromatogram of 100 ppm Brazilin standard (above) and 100 ppm extract (below).

DPP-IV inhibitory test demonstrated that Caesalpinia sappan, Cinchona officinalis, Muntingia calabura, Phyllanthus niruri, Psidium guajava and Rheum palmatum had inhibitory activity. The highest inhibitory activity of samples was obtained from Caesalpinia sappan extracts with a percent inhibition value of $84.25 \%$. The percent inhibition values of Caesalpinia sappan were not much different than the percent inhibition of Sitagliptin as a positive control (85.18\%). This shows that Caesalpinia sappan heartwood extract inhibits the activity of DPP-IV as well as Sitagliptin. The heartwood part of this plant contains brazilin. Brazilin standard solution was tested for its inhibitory activity against DPP-IV enzyme to strengthen the results of the Caesalpinia sappan extract inhibitory test. Brazilin standard solutions show significant inhibitory results of $78.30 \%$ on DPP-IV enzymes. These results prove that brazilin in Caesalpinia sappan extract has potential DPP-IV inhibitory activity. Some studies have suggested that the possible mechanism to explain inhibitory activity of brazilin in Caesalpinia sappan against DPP-IV enzyme is associated with insulin action. With the presence of insulin, brazilin can increase the rate of lipogenesis, glucose oxidation and regulate the enzymatic processes involved in glucose metabolism. Brazilin is associated with enhancement of insulin receptor function by a decrease in serin phosphorylation. ${ }^{17}$ Other studies have also reported that brazilin can stimulate glucose transport in vitro and decrease gluconeogenesis in hepatocytes isolated from diabetic rats. Brazilin is also reported to inhibit aldose reductase activity. ${ }^{18}$

Extract rich-in tannin, such as Cinchona officinalis, Muntingia calabura, Phyllanthus niruri, Psidium guajava and Rheum palmatum also showed potent inhibitory activity. The assay gave false-positive results if tannins were present. Based on research, it has been known that tannins inhibit enzymes. ${ }^{17}$ Tannins give positive results in certain tests because of their reaction with enzyme proteins. Tannin is known to have specific properties to precipitate protein and non-specific inhibitory activity for some hydrolytic enzymes such as lipase, $\alpha$-glucosidase, $\alpha$-amylase and invertase. ${ }^{17-19}$ DPP-IV enzyme is a class of protein, that can react and bind to tannin and form precipitate, so the enzyme activity decreases as a result of enzyme complexation. A study by Adamczyk et al. found that tannin are more than just inhibitors, but rather modifiers of enzyme activity. ${ }^{20}$ Removal of tannin and activity assay of the extract were conducted to prove DPP-IV inhibitory activity and to remove false-positive result caused by enzyme inhibition due the formation of tannin-substrate complexes on the extract. Percent inhibition of the Caesalpinia sappan extract (without tannin) was $74.16 \%$, while the percent inhibition of other extracts was decreased significantly. These results indicate that tannins have a significant effect against lowering inhibition activity of Cinchona officinalis, Muntingia calabura, Phyllanthus niruri, Psidium guajava and Rheum palmatum and have no significant effect on the activity of DPP-IV enzyme inhibition of Caesalpinia sappan extract. The response of enzymes against tannins varied depending on the enzyme. The enzyme affinity varies with tannins and the influence of unknown tannins on a given enzyme is unpredictable. ${ }^{21}$ Our in vitro study demonstrated an appreciable inhibitory activity present in 10 samples.

HPLC analysis showed that brazilin content on Caesalpinia sappan extracts was $91.94 \%$. High levels of brazilin in the extract showed that brazilin is a major compound in Caesalpinia sappan heartwood and this has been confirmed by other studies. ${ }^{22}$ Brazilin is a responsible compound for the activity of DPP-IV inhibition of Caesalpinia sappan extract and further research is necessary to determine the $\mathrm{IC}_{50}$ value and other possible activities of brazilin in Caesalpinia sappan extract.

\section{CONCLUSION}

Caesalpinia sappan, Muntingia calabura, Rheum palmatum, Phyllanthus niruri, Psidium guajava and Cinchona officinalis show the strong inhibition activity of DPP-IV. Based on the above-mentioned results, the ethanolic extract of Caesalpinia sappan has a potential effect as an antidiabetic agent.

\section{ACKNOWLEDGEMENT}

This research was supported by Directorate of Research and Community Engagement, Universitas Indonesia via Hibah PITTA 2018.

\section{CONFLICT OF INTEREST}

The Authors have no conflict of interest to declare.

\section{ABBREVIATIONS}

HPLC: High Performance Liquid Chromatography; DPP-IV: Dipeptidyl peptidase IV; FDA: Food and Drug Administration; GLP-1: GlucagonLike Peptida-1; Gly-Pro-AMC : Glicyl-Pro-Aminomethylcoumarin.

\section{REFERENCES}

1. Gao Y, Zhu J, Li Z, ZhuW, Shi J, Jia Q, et al. Recent progress in natural products as DPP-4 inhibitors. Future Med Chem. 2015;7(8):1079-89.

2. Arulselvan P, Amynurliyana H, Ghofar A, Firdaus M, Halim A, Syafiq M, et al. Antidiabetic therapeutics from natural source: A systematic review. Biomed Prev Nutr. 2014;4(4):607-17.

3. Borde MK, Mohanty IRAY, Suman RK, Deshmukh YA. Dipeptydil peptidase-iv inhibitory activities of medicinal plants. Asian J Pharm Clin Res. 2016;9(3):1-3.

4. Elya B, Handayani R, Sauriasari R, Azizahwati, Hasyyati US, Permana IT, et al. Antidiabetic activity and phytochemical screening of extracts from Indonesian plants by inhibition of alpha amylase, alpha glucosidase and dipeptidy peptidase iv. Pakistan J Biol Sci. 2015;18(6):279-84. 
5. Chang CLT, Lin Y, Bartolome AP, Chen YC, Chiu SC, Yang WC. Herbal therapies for type 2 diabetes mellitus: Chemistry, biology and potential application of selected plants and compounds. Evidence-Based Complement Altern Med. 2013;2013.

6. Jones MR, Hall OM, Kaye AM, Kaye AD. Drug-induced acute pancreatitis: A review. Ochsner J. 2015;15(1):45-51.

7. Riyanti S, Suganda AG, Sukandar EY. Dipeptydil peptidase-iv inhibitory activity of some Indonesian medicinal plants. Asian J Pharm Clin Res. 2016;9(2):2-4.

8. Modak M, Dixit P, Londhe J, Ghaskadbi S, Devasagayam TPA. Indian herbs and herbal drugs used for the treatment of diabetes. J Clin Biochem Nutr. 2007:40(3):163-73.

9. Bharti SK, Krishnan S, Kumar A, Rajak KK, Murari K, Bharti BK, et al. Antihyperglycemic activity with dpp-iv inhibition of alkaloids from seed extract of Castanospermum australe: investigation by experimental validation and molecular docking. Phytomedicine. 2012;20(1):24-31.

10. Pereira AC, Arruda MSP, da Silva EAS, da Silva MN, Lemos VS, Cortes SF. Inhibition of $\alpha$-glucosidase and hypoglycemic effect of stilbenes from the amazonian plant Deguelia rufescens var. urucu (Ducke) AMG Azevedo. Planta Med. 2014;78(01):36-8.

11. Szkudelski T, Szkudelska K. Anti-diabetic effects of resveratrol. Ann N Y Acad Sci. 2011;1215(1):34-9

12. Wang B, Liu T, Wu Z, Zhang L, Sun J, Wang X. Synthesis and biological evaluation of stilbene derivatives coupled to $\mathrm{NO}$ donors as potential antidiabetic agents. J Enzyme Inhib Med Chem 2018;33(1):416-23.

13. Rosalie IO, El E. Antidiabetic potentials of common herbal plants and plant products . A Glance Int J Herb Med. 2016;4(4): 90-7.

14. www. caymanchem.com. [homepage on the Internet]. DPP (IV) Inhibitor Screening Assay Kit. (700210) [cited 2018 Jul 20].

15. Prommajak T, Leksawasdi N. Optimizing tannin precipitation in cashew apple juice. CMU J Nat Sci 2018;17:13-23.

16. Settharaksa S, Monton C, Pathompak P, Madaka F. HPLC method validation for determination of brazilin in Caesalpinia sappan L. heartwood extract. TJPS. 2017;41:141-4.

17. Kim SG, Kim YM, Khil LY, Jeon SD, So DS, Moon CH, et al. Brazilin inhibits activities of protein kinase $\mathrm{c}$ and insulin receptor serine kinase in rat liver. Arch Pharm Res. 1998;21(2):140-6.

18. Barrett A, Ndou T, Hughey CA, Straut C, Howell A, Dai Z, et al. Inhibition of $\alpha$-amylase and glucoamylase by tannins extracted from cocoa, pomegranates, cranberries and grapes. J Agric Food Chem. 2013;61(17):1477-86.

19. Gonçalves R, Mateus N, de Freitas V. Inhibition of a -amylase activity by condensed tannins. Food Chem. 2011;125:665-72.

20. Bi WP, Man HB, Man MQ. Efficacy and safety of herbal medicines in treating gastric ulcer: A review. World J Gastroenterol. 2014;20(45):17020-8.

21. Adamczyk B, Simon J, Kitunen $V$, Adamczyk S, Smolander A. Tannins and their complex interaction with different organic nitrogen compounds and enzymes: old paradigms versus recent advances. Chem Pub Soc Europe. 2017;6(5):610-4.

22. Lioe $H$, Adawiyah $D$, Anggraeni R. Isolation and characterization of the major natural dyestuff component of Brazilwood (Caesalpinia sappan L.). Int Food Res J. 2012;19(2):537-42.

Article History: Submission Date : 12-09-2018 ; Revised Date : 24-12-2018; Acceptance Date : 25-01-2019.

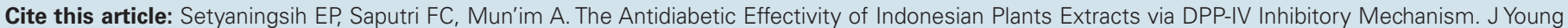
Pharm. 2019;11(2):161-4. 